\title{
Countermeasures of Cultivating Students Innovative Ability in Physiology and Biochemistry
}

\author{
Zhang Jin ${ }^{1}$, Wang Meng ${ }^{1}$, Lin $\mathrm{Na}^{1}$, Du Hang ${ }^{1}$

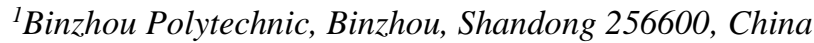 \\ Email:'zhangjinbz@163.com
}

\begin{abstract}
The progress of modern medical science and technology has put forward higher requirements for the cultivation of medical talents. Under the background of the new era, the ability of scientific research and innovation is a kind of ability that medical students should have. Cultivating the ability of scientific research and innovation of medical students is also the key content of the current domestic medical education system reform. In this paper, how to cultivate students' innovation ability in physiology teaching is explored, hoping to provide reference for future physiology teaching.
\end{abstract}

Keywords: physiology teaching, innovation ability, training methods

\section{INTRODUCTION}

The sustainable development of society needs the help of human knowledge innovation. The outline of the 12th Five Year Plan of the people's Republic of China clearly puts forward that "we should strengthen the innovation of education methods, attach importance to the cultivation of students' scientific spirit, innovation ability and creative thinking, and strive to cultivate innovative scientific and technological talents". Physiology is a compulsory basic subject for all medical students, which mainly studies the normal function and activity of biological body. Under the traditional teaching mode, physiology teachers often impart knowledge to students by indoctrination, requiring students to master knowledge through memory, ignoring the cultivation of students' innovation ability.

\subsection{Related Work}

Improving teachers' comprehensive quality is the core of cultivating innovative medical talents. In order to cultivate students' innovative thinking and ability, we must first build a team of teachers with high comprehensive quality[2]. As a teacher, we should change the concept of education and constantly adjust and improve our knowledge structure by strengthening theoretical research. We should actively study theoretical knowledge, master the methods that can cultivate students' innovative ability, and then through adjusting the teaching content, teaching methods and teaching mode, we can infiltrate the cultivation of innovative ability into the whole process of physiology teaching. In order to improve their academic level, physiology teachers should actively participate in various professional research work, adhere to collective lesson preparation, and understand and master the problems that may appear in the teaching process in advance. There are many students who are eager for knowledge in the student group. In the face of these students, teachers should not only have solid professional basic knowledge, but also have strong language expression ability[1]. Only in this way can they better explain questions for these students.

\subsection{Our Contribution}

Training medical students' innovative ability in physiological theory teaching.

Carry out PBL teaching method and case teaching method. The problem-based teaching method, also known as PBL teaching, is actually a kind of teaching method that takes problems as the basis of teaching and carries out teaching around students. The application of this teaching method can obviously improve students' innovation ability and enhance students' creative thinking. PBL teaching method encourages students to carry out autonomous learning with problems. Specifically, in the week before formal teaching, teachers can assign students some questions with strong vitality and students are interested in, such as: what are the differences between dwarfism and nerdy? Organize the students to divide into several groups, and ask the students to study the related chapters of physiology in the form of groups after class. If they have any questions or don't understand, encourage the students to complete in the way of group discussion or consulting literature and materials. Before the formal teaching, teachers can reserve a certain time to talk about the results of their study 
and discussion. If they encounter disputes, they can appropriately carry out micro debates. After the students complete the communication, teachers will give further induction, summary and evaluation, and answer the difficult problems that students have not solved. The application of PBL teaching method fully reflects the dominant position of students, and helps to create a more open classroom atmosphere, help students better understand and master relevant professional knowledge, cultivate students' team spirit, and improve students' innovation ability by stimulating their innovation and exploration spirit. In practical teaching, teachers can help students combine theoretical knowledge with clinical practice by introducing appropriate cases, help students expand their knowledge and stimulate their interest in learning[3]. From the physiological point of view, the emergence of disease is usually the body in certain conditions, affected by the relevant causes, self-regulation disorder, eventually leading to the emergence of abnormal life activities. In order to better understand the disease, we must fully understand and master the normal life activities and laws of the body. Through case explanation, help students to extract physiological knowledge points, and gradually cultivate students' ability of reasoning and judgment. Reasonable teaching methods can give full play to students' subjectivity in learning. The more fully the subjectivity is brought into play, the stronger the students' autonomy and creativity in learning will be, and the better the learning effect will be[4]. Physiological experiments can make students directly contact with organisms and carefully study life phenomena, which can effectively attract students' attention and arouse their interest in learning, It is an important way to cultivate students' various abilities

Actively carry out network teaching. With the development of Internet information technology, network teaching has been widely used in the process of health education and teaching. In order to help students better grasp the knowledge of physiology curriculum and gradually cultivate their innovative ability, teachers can set up the excellent course website of physiology for students. Give full play to the advantages of network resources, present abstract, complex and difficult to understand knowledge to students in more intuitive and image ways such as pictures and videos, create more suitable learning scenes for students, stimulate students' desire for knowledge, and promote students to obtain positive psychological experience. The teaching resources included in the website are very rich, and students can find relevant courses according to their own learning needs and complete their own learning independently; If there are problems in the learning process, teachers can organize students to discuss in QQ or wechat way, solve the problems and arouse students' interest in physiology learning. Organize students to update web pages by searching for materials and collecting materials, and guide students to participate in the updating and maintenance of the network. The application of interactive network teaching can realize good interaction between teachers and students through forum message and QQ answer, help students acquire new knowledge, mobilize students' interest in learning, and lay a good foundation for cultivating students' innovation ability.

\section{BACKGROUND}

Training the innovative ability of medical students in physiological experiment teaching.Create physiological situations. In the traditional teaching of physiology, students play a role mostly as spectators. Their participation in teaching is very low, and the final teaching effect is very unsatisfactory. In order to change the role of passive acceptance, guide students to actively participate in the process of physiological experiment teaching

To show the main position of students in teaching activities, teachers must change the traditional teaching mode and innovate teaching methods. In this way, creating a real physiological situation is a very effective teaching method. By creating a real physiological situation, teachers can help teachers transform the plain and abstract knowledge into vivid and vivid knowledge and deepen students' understanding, In this process, teachers can stimulate students' interest in exploration if they guide them properly[5]. For example, teachers can show students some defective articles or equipment, encourage students to describe the deficiencies of these articles or equipment through observation, and then say that they can make up for these deficiencies, so that students' enthusiasm for innovation can be aroused. For example, one is to blow air to the balloon constantly. When the volume of the balloon increases to a certain extent, the balloon breaks down. Please think about how to avoid the balloon rupture? Second, a small hole is made with a needle in the balloon. Although it is blowing continuously, the balloon is not blowing very much. What is the reason for this? Students can think deeply about the content of breath (pneumothorax) in combination with the relevant content. In the practice of physiology teaching, teachers can create real physiological situations through other methods, such as case method, storytelling method, experiment method, personal experience method, etc. Through creating real and interesting situations, students' interest in learning is aroused, students are guided to the questioning state of thinking and enlighten students' innovative thinking.

We will actively carry out comprehensive experiments. The development of physiological experiment teaching can deepen the students' understanding of theoretical knowledge, consolidate the students' learning and improve the 
students' ability of hands-on operation. Traditional physiology teaching pays more attention to basic verification experiment, with a single content and form. There are some problems of repetition and cross between different disciplines. In experimental teaching, teachers often ask for them. Students operate and learn according to the requirements of teachers. Most of the experimental operations are mechanical imitation, The subjective initiative of learning has not been effectively stimulated, and the cultivation of innovation ability has been seriously frustrated. In order to improve the teaching quality of experimental classroom effectively, teachers need to delete the repetitive and verifiable experimental contents for students, and add some comprehensive experiments as much as possible. Comprehensive experiments can connect relevant theoretical knowledge with animal experiments, and cultivate students' comprehensive ability of interdisciplinary. For example, when conducting the experimental teaching of "neurohumoral regulation of cardiovascular activities and the influence of efferent nervous system drugs" in rabbits, teachers can review the basic theoretical knowledge of nervous system and blood circulation system with students before formal teaching, help students understand the background of the experiment, broadcast experimental videos for students and explain the standardized operation for students, Students will be curious about the anesthesia fixation, nerve separation and vascular intubation of rabbits by watching the video, which will stimulate the students' interest in the experiment. In the experiment, the teacher should explain the specific steps and precautions of the experiment carefully for the students, encourage students to operate, find the answers while they look for the answers, and the teachers will observe carefully, Give help and guidance to imperfect places in time. The development of comprehensive experiment has enhanced the students' team spirit, cultivated and improved the students' ability of hands-on operation, and helped them to better master the relevant knowledge of experimental principles and instrument use, and effectively improved the comprehensive literacy level of students.

\subsection{Probabilistic Automata}

Reform the examination mode of experimental course. In traditional teaching mode, the basis of physiological experiment results of medical students is usually the final operation examination and daily experimental report. Such experimental results are too single to evaluate the comprehensive ability of students. With the deepening of physiology teaching reform, in recent years, teachers also cover group test, comprehensive operation test, experimental report, operation competition and other contents when evaluating students' experimental results. Through the usual test, the students have mastered the basic theory of the experiment. When correcting the experimental report, teachers should pay attention to the analysis of the experimental results, so as to evaluate the students' observation ability, analysis ability and summary ability[6]. Organize and carry out physiological operation competitions regularly, strengthen training of basic skills of medical students, mobilize students' enthusiasm and initiative in learning. When setting the final examination content, they should also integrate the operation steps, basic principles and instrument use, and put forward experimental requirements to complete specific experimental operation within the specified time, This kind of experiment test not only examines the students' hands-on ability, but also the ability of team cooperation. In order to improve the comprehensive, fair and objective of the evaluation, the proportion of final examination and daily experiment results is designed reasonably. Generally speaking, the final operation test results account for $60 \%$ and the experimental results account for $40 \%$ of the total results.

Encourage medical students to carry out independent experimental design and participate in scientific research. Based on the guidance of teachers, medical students should actively carry out independent experimental design, and actively participate in various related scientific research work. Experimental design includes five stages: project approval, experimental design, pre experiment and formal experiment, data sorting, summary and thesis writing. First, students need to put forward their own ideas by consulting relevant literature and materials, and then actively communicate with teachers to demonstrate the feasibility of the subject and determine the subject. In this process, students can contact with the frontier knowledge and technology of physiology, greatly broaden their horizons, and deeply tap the students' innovative potential. The second is to solve problems through the design and implementation of experiments. At the same time, students also get the way to solve problems. Under the guidance and help of teachers, students can use multidisciplinary knowledge to complete the whole experiment. Third, through the statistical analysis of experimental data, thesis writing, improve students' ability to obtain information, analyze and deal with problems, cultivate students' rigorous scientific attitude. As an exploratory learning mode, self-designed experiments can stimulate students' innovative thinking, cultivate and improve their innovative ability.

\section{CONCLUSION}

To sum up, health schools undertake the important task of personnel training. In order to continuously output high-quality and high-quality innovative scientific research talents for the society, health schools must pay attention to the cultivation of 
students' innovative ability. As a physiology teacher, in the specific practice of physiology teaching, we must change the traditional teaching concept, innovate teaching mode and method, and focus on cultivating and improving students' innovative ability in order to stimulate students' innovative thinking.

\section{REFERENCES}

[1] Ouyang Yunfan. On the reform of physiology teaching and the cultivation of Higher Vocational Students' innovative ability[J]. Science and technology information, 2019,19:152.

[2] Wen Libo. Training medical students' ability of scientific research and innovation in physiology teaching $[\mathrm{J}]$. science and technology innovation guide, 2018,8:203.

[3] Zhang Shan. Cultivation of scientific research and innovative thinking ability in Physiology Teaching [J]. Curriculum education research: Research on learning and teaching methods, 2019,11:31.

[4] $\mathrm{Xu}$ geyang. Cultivation of scientific research and innovative thinking ability in Physiology Teaching $[\mathrm{J}]$. Basic medical education, 2018,12:1047-1049.

[5] Wang Qinghua. The cultivation of students' innovative thinking ability in history teaching in middle schools [J]. Scientific consultation (education and scientific research), 2020,1.

[6] Han Bing. Research on teacher training program of TAFE College in Australia [D]. Northeast Petroleum University, June 2019.

[7] P. Xu, J. Cao, et. al., Quantum chemical study on the adsorption of megazol drug on the pristine BC3 nanosheet, Supramolecular Chemistry, 33(2021)63-69. 